\title{
ANALISIS TINGKAT RISIKO BAHAYA K3 PADA PENGELOLAAN APARTEMEN MENGGUNAKAN METODE HAZARD OPERABILITY STUDY (HAZOPS)
}

\author{
Sofian Bastuti * \\ Program Studi Teknik Industri, Fakultas Teknik, Universitas Pamulang \\ Email: dosen00954@unpam.ac.id \\ Artikel masuk : 18-10-2020 \\ Artikel direvisi : 08-01-2021
${ }^{*}$ Penulis Korespondensi \\ Artikel diterima : 14-01-2021
}

\begin{abstract}
Abstrak -- Perusahaan pengelolaan apartemen ini beralamat di Jalan Marsekal Suyadarma No. 1 Tangerang adalah salah satu perusahaan yang bergerak dibidang pengelolaan gedung (Property Management) yang mempunyai enam divisi. Setiap divisi mempunyai potensi bahaya sebagai indikasinya adalah terjadi 18 kasus kecelakaan dalam kurun waktu 2014 sampai 2017. Riset ini bertujuan untuk mengidentifikasi potensi bahaya yang menyebabkan kecelakaan kerja. Dalam riset ini upaya untuk pencegahan terjadinya kecelakaan kerja akan dilakukan menggunakan metode Hazard Operability Study (HAZOPS). Hasil dari penelitian ini adalah terdapat 45 potensi bahaya kecelakaan kerja yang ada di enam divisi yaitu divisi Staff management building 31\%, Divisi Engineering 18\%, Divisi Parking 9\%, Divisi Housekeeping 24\%, Security 2\%, Vendor/Subcon 16\%. Divisi yang mempunyai jumlah potensi bahaya terbanyak yaitu divisi Staff management building 31\%. Kemudian untuk tingkat risiko Tinggi 33\%, tingkat risiko Sedang 51\%, tingkat risiko rendah $16 \%$. Jadi potensi bahaya yang tingkat risiko ekstrim tidak ada. Perbaikan dilakukan dengan mengacu ke hirarki pengendalian potensi bahaya: eliminasi, substitusi, rekayasa engineering, pengendalian administratif dan alat pelindung diri $(A P D)$.
\end{abstract}

Kata kunci: Apartemen; HAZOPS; Tingkat Risiko

\begin{abstract}
This apartment management company is located at Jalan Marsekal Suyadarma No. 1 Tangerang is a company engaged in building management (Property Management) which has six divisions. Each division has potential hazards as an indication that there have been 18 accidents from 2014 to 2017. This study aims to identify potential hazards that cause work accidents. In this study, efforts to prevent work accidents will be carried out using the Hazard Operability Study (HAZOPS) method. The results of this study are that there are 45 potential hazards of work accidents in six divisions, namely the Staff management building division 31\%, the Engineering Division 18\%, the Parking Division 9\%, the Housekeeping Division 24\%, Security 2\%, Vendor / Subcon 16\%. The division that has the highest number of potential hazards is the Staff management building division at $31 \%$. The high-risk level is 33\%, the risk level Medium 51\%, and 16\% low-risk level. So the potential for danger for which extreme risk level does not exist. Improvement is carried out by referring to the hazard potential control hierarchy: elimination, substitution, engineering, administrative control, and personal protective equipment (PPE).
\end{abstract}

Keywords: Apartement, HAZOPS, Risk Level

\section{PENDAHULUAN}

Pada tahun 2017 informasi International Labour Organization (ILO) mengatakan kalau 2, 78 juta pekerja wafat pertahun sebab musibah kerja serta penyakit akibat kerja. Dekat 2,4 juta $(86,3 \%)$ dari kematian ini disebabkan penyakit akibat kerja, sedangkan lebih dari 380.000 $(13,7 \%)$ diakibatkan musibah kerja. Tiap tahun, terdapat kebanyakan musibah kerja non parah dibanding musibah kerja parah. Musibah non parah diperkirakan dirasakan 374 juta pekerja per tahun, serta banyak dari musibah ini mempunyai 
dampak yang sungguh-sungguh terhadap bagian pemasukan para pekerja (Ulva, 2019). Tahuntahun sebelumnya seperti tahun 2012, ILO menyatakan angka kematian akibat kecelakaan dan penyakit akibat kerja (PAK) sebanyak 2 juta permasalahan tiap tahun (Achada \& Anis, 2016; Siddiqui et al., 2014; Sugarindra et al., 2017). Permasalahan keselamatan dan kesehatan kerja (K3) secara universal di Indonesia masih kerap terabaikan (Bastuti, 2020; Supriyadi \& Ramdan, 2017). Hal ini ditandai dengan banyaknya total kecelakaan kerja. Keadaan keselamatan dan kesehatan kerja (K3) perusahaan di Indonesia secara universal diproyeksikan termasuk sedikit, padahal pekerja adalah indikator penting bagi kegiatan perusahaan (Alfatiyah et al., 2017; Supriyadi et al., 2015).

Biasanya di semua area kerja selalu terdapat bahaya yang bisa mengancam keselamatan maupun kesehatan pekerja (Arif \& Syahri, 2014; Zhang et al., 2015). Nyaris tidak ada area kerja yang sama sekali terhindar dari bahaya. Bahaya di area kerja bisa diketahui dari bahan yang dipakai untuk bekerja, proses kerja serta limbah yang dihasilkan (Ahmad et al., 2016; Carrascosa et al., 2016). Dimana pekerja harus dapat memahami arti pentingnya keselamatan dan kesehatan kerja untuk melindungi pekerja sehingga bisa meningkatkan kinerja perusahaan (Kim et al., 2015; Suhardi et al., 2018).

Perusahaan pengelolaan apartemen ini beralamat di Jalan Marsekal Suyadarma No. 1 Tangerang adalah pengelola gedung Apartemen Tamansari Skylounge, Operasional gedung Apartemen Tamansari Skylounge diawali pada akhir tahun 2014. Dalam menjalankan pengelolaan gedung apartemen Tamansari Skylounge Tangerang masih terjadi kecelakaan dalam proses pekerjaan. Berikut ini adalah data kejadian kecelakaan kerja dari tahun 2014 sampai 2017 (Gambar 1).

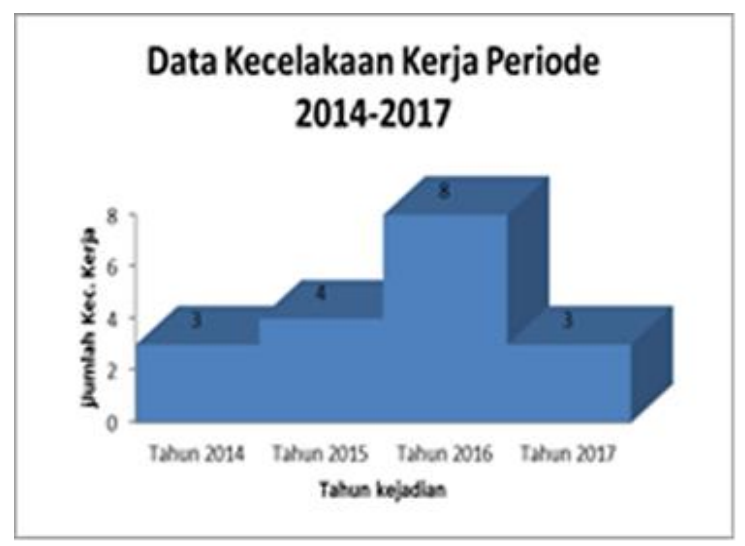

Gambar 1. Data Kecelakaan Kerja Periode 20142017
Trend kecelakaan kerja PT. Wika Realty apartemen Tamansari Skylounge masih fluktuatif, terutama dari tahun 2014 sampai 2016 terus meningkat. Di tahun 2017 mengalami penurunan jumlah kecelakaan kerja dan untuk tahun-tahun berikutnya diharapkan terus menurun. Dampak kecelakaan bagi pekerja adalah menyebabkan rasa trauma, cacat bahkan sampai kematian, sedangkan bagi perusahaan sendiri dampaknya akan menurunkan produktivitas atau lambatnya produksi.

Identifikasi potensi dan risiko bahaya di area tempat kerja mempunyai peranan yang penting untuk menurunkan kemungkinan kecelakaan yang terjadi. Tujuan riset ini yaitu untuk mengukur potensi bahaya dan tingkat kecelakaan kerja pada pengelolaan apartemen dengan menggunakan metode HAZOPS. Hasil identifikasi ini diharapkan mampu menurunkan potensi dan risiko bahaya yang terjadi pada aktivitas pada setiap divisi.

\section{METODE PENELITIAN}

Riset ini merupakan jenis riset deskriptif yaitu riset yang berupaya mengartikan suatu indikasi, perihal kejadian yang terjalin waktu sekarang. Riset deskriptif memusatkan perhatian kepada permasalahan aktual pada waktu riset berlangsung. Variabel yang diteliti sebanyak 3 variabel yaitu likelihood, exposure dan Concequency (Cameron et al., 2017; Mansur \& Nasution, 2016).

Teknik pengumpulan data biasanya menggunakan pengamatan dan interview. Metode pengumpulan data seperti pengamatan langsung ke area kerja dengan tujuan mendapatkan data aktual yang diperlukan dalam riset ini. Interview dilakukan secara langsung dengan para pekerja tetap, pekerja harian atau pekerja kontrak yang ada di Perusahaan pengelolaan apartemen.

Pada penelitian ini akan dianalisa menggunakan metode Hazard Operability Study (HAZOPS). HAZOPS adalah suatu cara mengidentifikasi bahaya yang terstruktur dan terintegrasi untuk mengidentifikasi berbagai masalah yang mengancam alur proses dan risiko yang terdapat pada suatu alat yang dapat menimbulkan risiko merugikan bagi fasilitas pada sistem dan manusia. langkah-langkahnya sebagai berikut (Alfatiyah et al., 2017; Restuputri \& Sari, 2015):

1. Mengidentifikasi pekerjaan/Aktivitas

2. Mengidentifikasi uraian pekerjaan/Aktivitas

3. Mengidentifikasi temuan potensi bahaya

4. Mengidentifikasi dampak bahaya

5. Melakukan penilaian risiko (Risk Assessment Tingkat risiko $=$ Likelihood $x$ Exposure $x$ Concequency (1) 


\section{HASIL DAN PEMBAHASAN}

Perusahaan pengelolaan apartemen ini beralamat di Jalan Marsekal Suyadarma No. 1 Tangerang adalah perusahaan yang bergerak di bidang pengelolaan Gedung (Property Management) bertingkat. Dalam menjalankan pengelolaan gedung apartemen Tamansari Skylounge Tangerang diperlukan beberapa divisi seperti engineering, parking, housekeeping, security dan staff management building untuk menjalankan visi dan misi organisasi perusahaan agar tercapai.

Tabel 1. Jenis dan Jumlah Kegiatan

\begin{tabular}{|c|c|c|}
\hline Divisi & Aktivitas & Jumlah \\
\hline $\begin{array}{c}\text { Staff } \\
\text { Manage- } \\
\text { ment } \\
\text { building }\end{array}$ & $\begin{array}{l}\text { Penggunaan alat elektronik } \\
\text { (Komputer) } \\
\text { Penggunaan aksesoris listrik } \\
\text { (kabel, stopkontak) } \\
\text { Penggunaan Printer } \\
\text { Pengarsipan Berkas }\end{array}$ & 4 \\
\hline Engineering & $\begin{array}{l}\text { Pemeliharaan AC } \\
\text { Penggunaan Scaffolding } \\
\text { Perawatan Graoudtank dan } \\
\text { Rooftank } \\
\text { Perbaikan aliran listrik gedung }\end{array}$ & 4 \\
\hline Parking & $\begin{array}{l}\text { Pengaturan Area Parkir } \\
\text { Pengaturan Lalu Lintas }\end{array}$ & 2 \\
\hline $\begin{array}{l}\text { House- } \\
\text { keeping }\end{array}$ & $\begin{array}{l}\text { Pembersihan area dalam } \\
\text { Gedung } \\
\text { Pembuangan Sampah } \\
\text { Pencucian Alat Makanan } \\
\text { Penggunaan Chemical } \\
\text { Pembersih Lantai }\end{array}$ & 4 \\
\hline $\begin{array}{l}\text { Security } \\
\text { Vendor/ } \\
\text { Subcon }\end{array}$ & $\begin{array}{l}\text { Keamanan Gedung } \\
\text { Perawatan Genset } \\
\text { Pengendalian Hama (Pest } \\
\text { Control) } \\
\text { Pembuangan Limbah Sewage } \\
\text { Treatment Plant (STP) }\end{array}$ & 1 \\
\hline Jumlah & & 18 \\
\hline
\end{tabular}

Setiap divisi pasti mempunyai potensi sumber bahaya waktu melakukan proses pekerjaan 6 divisi yang bekerja di apartemen Tamansari Skylounge Tangerang memiliki jenis kegiatan adalah divisi Staff Management Building, Engineering, Housekeeping dan vendor/subcon sebanyak 4 jenis kegiatan, divisi parking dengan 2 jenis kegiatan dan divisi security dengan 1 jenis kegiatan (Tabel 1).

Identifikasi kemungkinan potensi dan risiko bahaya dilakukan pengamatan lapangan secara langsung dan interview terhadap pekerja yang terlibat langsung dan mengetahui proses kerja, Perangkingan dengan memperhatikan kriteriakriteria tingkat kemungkinan (Tabel 2) dan keparahan (Tabel 3). Hasil penilaian tingkat risiko dikategorikan dalam risk matriks (Gambar 2) untuk menentukan tingkat risiko dari sebuah aktivitas.
Tabel 2. Kriteria Likelihood (Kemungkinan)

\begin{tabular}{|c|c|c|c|}
\hline \multirow{2}{*}{ Level } & \multirow{2}{*}{ Kriteria } & \multicolumn{2}{|c|}{ Deskripsi } \\
\hline & & Qualitative & Semi Qualitative \\
\hline 1 & $\begin{array}{l}\text { Jarang } \\
\text { terjadi }\end{array}$ & $\begin{array}{c}\text { Dapat dipikirkan } \\
\text { tetapi tetapi tidak } \\
\text { hanya saat keadaan } \\
\text { ekstrim }\end{array}$ & $\begin{array}{l}\text { Kurang dari } 1 \\
\text { kali dalam } 10 \\
\text { tahun }\end{array}$ \\
\hline 2 & $\begin{array}{c}\text { Kemungki- } \\
\text { nan kecil }\end{array}$ & $\begin{array}{c}\text { Belum terjadi tetapi } \\
\text { bisa muncul/terjadi } \\
\text { pada suatu waktu }\end{array}$ & $\begin{array}{l}\text { Terjadi } 1 \text { kali } \\
\text { per } 10 \text { tahun }\end{array}$ \\
\hline 3 & Mungkin & $\begin{array}{l}\text { Seharusnya terjadi } \\
\text { dan mungkin telah } \\
\text { terjadi/muncul disini } \\
\text { atau di tempat lain }\end{array}$ & $\begin{array}{c}1 \text { kali per } 5 \\
\text { tahun sampai } \\
1 \text { kali } \\
\text { pertahun }\end{array}$ \\
\hline 4 & $\begin{array}{c}\text { Kemungkinan } \\
\text { besar }\end{array}$ & $\begin{array}{l}\text { Dapat terjadi dengan } \\
\text { mudah, mungkin } \\
\text { muncul dalam } \\
\text { keadaan yang paling } \\
\text { banyak terjadi }\end{array}$ & $\begin{array}{l}\text { Lebih dari } 1 \\
\text { kali per tahun } \\
\text { hingga } 1 \text { kali } \\
\text { per bulan }\end{array}$ \\
\hline 5 & Hampir pasti & $\begin{array}{c}\text { Sering terjadi, } \\
\text { diharapkan muncul } \\
\text { dalam keadaan yang } \\
\text { paling banyak terjadi }\end{array}$ & $\begin{array}{l}\text { Lebih dari } 1 \\
\text { kali per bulan }\end{array}$ \\
\hline
\end{tabular}

Tabel 3. Kriteria Concequency (Keparahan)

\begin{tabular}{|c|c|c|c|}
\hline \multirow{2}{*}{ Level } & \multirow{2}{*}{ Kriteria } & \multicolumn{2}{|l|}{ Deskripsi } \\
\hline & & Keparahan Cidera & Hari Kerja \\
\hline 1 & $\begin{array}{c}\text { Tidak } \\
\text { signifikan }\end{array}$ & $\begin{array}{c}\text { Kejadian tidak } \\
\text { menimbulkan kerugian } \\
\text { atau cidera pada manusia }\end{array}$ & $\begin{array}{c}\text { Tidak } \\
\text { menyebabkan } \\
\text { kehilangan hari } \\
\text { kerja }\end{array}$ \\
\hline 2 & Kecil & $\begin{array}{l}\text { Menimbulkan cidera } \\
\text { ringan, kerugian kecil dan } \\
\text { tidak menimbulkan } \\
\text { dampak serius terhadap } \\
\text { kelangsungan bisnis }\end{array}$ & $\begin{array}{l}\text { Masih dapat } \\
\text { bekerja pada } \\
\text { hari.shift yang } \\
\text { sama }\end{array}$ \\
\hline 3 & Sedang & $\begin{array}{l}\text { Cidera berat dan dirawat di } \\
\text { rumah sakit, tidak } \\
\text { menimbulkan cacat tetap, } \\
\text { kerugian finansial sedang }\end{array}$ & $\begin{array}{c}\text { Kehilangan hari } \\
\text { kerja di bawah } \\
3 \text { hari }\end{array}$ \\
\hline 4 & Berat & $\begin{array}{l}\text { Menimbulkan cidera parah, } \\
\text { cacat tetap dan kerugian } \\
\text { finansial besar serta } \\
\text { menimbulkan dampak } \\
\text { serius terhadap } \\
\text { kelangsungan usaha }\end{array}$ & $\begin{array}{c}\text { Kehilangan hari } \\
\text { kerja } 3 \text { hari } \\
\text { atau lebih }\end{array}$ \\
\hline 5 & Bencana & $\begin{array}{l}\text { Mengakibatkan korban } \\
\text { meninggal dan kerugian } \\
\text { parah bahkan dapat } \\
\text { menghentikan kegiatan } \\
\text { usaha selamanya }\end{array}$ & $\begin{array}{l}\text { Kehilangan } \\
\text { hari kerja } \\
\text { selamanya }\end{array}$ \\
\hline
\end{tabular}

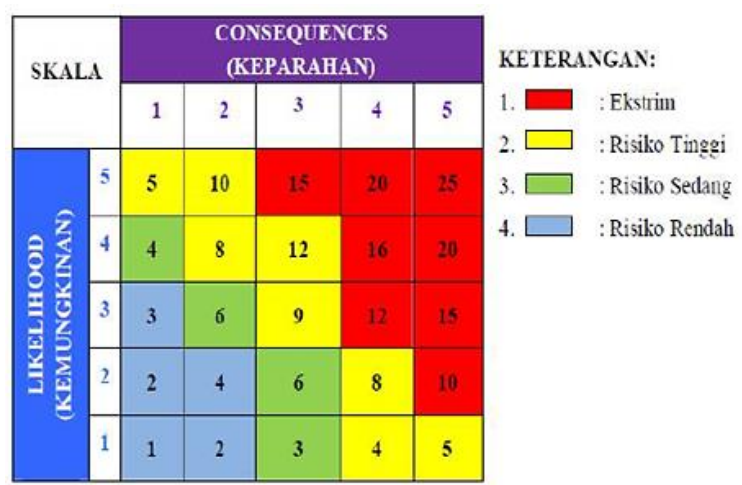

Gambar 2. Risk Matriks 
Proses penilaian risko pada tiap-tiap divisi PT. Wika Realty apartemen Tamansari Skylounge Tangerang bertujuan untuk mengetahui level risiko tiap-tiap aktivitas pada masing-masing divisi. Divisi Staff Management Building PT. Wika Realty apartemen Tamansari Skylounge Tangerang mempunyai 3 potensi bahaya yang mempunyai risiko tinggi, 9 mempunyai dampak risiko sedang dan 2 potensi bahaya dalam level rendah. Divisi Engineering mempunyai 5 potensi bahaya yang mempunyai risiko tinggi, 2 mempunyai dampak risiko sedang dan 1 potensi bahaya dalam level rendah. Divisi Parking mempunyai 4 potensi bahaya yang mempunyai dampak risiko sedang. Divisi Housekeeping mempunyai 2 bahaya yang memiliki risiko tinggi, 5 mempunyai dampak risiko sedang dan 4 potensi bahaya dalam level rendah. Divisi Security mempunyai 1 bahaya yang memiliki risiko tinggi. Divisi Vendor/Subcon mempunyai 4 potensi bahaya yang mempunyai risiko tinggi, dan 3 mempunyai dampak risiko sedang (Tabel 4).

Tabel 4. Penilaian Risiko PT. Wika Realty Apartemen Tamansari Skylounge Tangerang

\begin{tabular}{|c|c|c|c|c|c|c|c|}
\hline Divisi & Aktivitas & Uraian Potensi Bahaya & Dampak Risiko & & $\begin{array}{l}\text { Risk } \\
\text { essn } \\
\text { C }\end{array}$ & $\begin{array}{r}n t \\
\mathrm{~S}\end{array}$ & $\begin{array}{l}\text { Risk } \\
\text { Level }\end{array}$ \\
\hline \multirow{14}{*}{$\begin{array}{c}\text { Staff } \\
\text { Managemen } \\
\text { Bulding }\end{array}$} & $\begin{array}{l}\text { Penggunaan } \\
\text { talat elektronik }\end{array}$ & $\begin{array}{l}\text { Terkena Pancaran Radiasi layar } \\
\text { monitor Komputer }\end{array}$ & Sakit pada mata & 4 & 1 & 4 & Sedang \\
\hline & (Komputer) & $\begin{array}{l}\text { Kesetrum Alat elektronik karena } \\
\text { tidak digunakan dengan benar }\end{array}$ & $\begin{array}{l}\text { Tubuh akan mengalami } \\
\text { kesemutan atau kejutan }\end{array}$ & 3 & 2 & 6 & Sedang \\
\hline & & $\begin{array}{l}\text { Konsleting pada Alat elektronik yang } \\
\text { berpotensi kebakaran }\end{array}$ & Kematian & 1 & 5 & 5 & Tinggi \\
\hline & & $\begin{array}{l}\text { Tersandung Kabel alat elektronik } \\
\text { terpasang tidak rapi }\end{array}$ & Cidera anggota tubuh & 3 & 2 & 6 & Sedang \\
\hline & $\begin{array}{l}\text { Penggunaan } \\
\text { aksesoris } \\
\text { listrik }\end{array}$ & $\begin{array}{l}\text { Mencabut steker dalam kondisi } \\
\text { tangan basah berpotensi tersengat } \\
\text { listrik }\end{array}$ & $\begin{array}{l}\text { Tubuh akan mengalami } \\
\text { kesemutan atau kejutan }\end{array}$ & 1 & 2 & 2 & Rendah \\
\hline & & $\begin{array}{l}\text { Kebakaran akibat dari material tidak } \\
\text { standar yang berdampak steker } \\
\text { lumer }\end{array}$ & Kematian & 1 & 5 & 5 & Tinggi \\
\hline & & $\begin{array}{l}\text { Instalasi kabel berantakan, tata letak } \\
\text { jelek/tidak rapi menghalangi jalan } \\
\text { kerja berpotensi kaki tersandung }\end{array}$ & Cidera anggota tubuh & 3 & 2 & 6 & Sedang \\
\hline & $\begin{array}{l}\text { Penggunaan } \\
\text { Printer }\end{array}$ & $\begin{array}{l}\text { Jari tangan terjepit catridge saat } \\
\text { pemindahan /pengangkatan printer }\end{array}$ & Cidera Tangan & 1 & 2 & 2 & Rendah \\
\hline & & Debu toner & $\begin{array}{l}\text { Sesak pernapasan, } \\
\text { menimbulkan batuk \& } \\
\text { bersin }\end{array}$ & 3 & 2 & 6 & Sedang \\
\hline & & $\begin{array}{l}\text { Tangan masuk ke dalam mesin } \\
\text { printer karena pengaman penutup } \\
\text { mesin printer tidak sesuai }\end{array}$ & Luka pada tangan & 3 & 2 & 6 & Sedang \\
\hline & $\begin{array}{l}\text { Pengarsipan } \\
\text { Berkas }\end{array}$ & $\begin{array}{l}\text { Tersandung karena tumpukan } \\
\text { berkas. }\end{array}$ & Anggota tubuh cidera. & 3 & 2 & 6 & Sedang \\
\hline & & $\begin{array}{l}\text { Penggunaan alat pelindung diri } \\
\text { yang tidak sesuai }\end{array}$ & $\begin{array}{l}\text { Cidera berat bahkan } \\
\text { bisa cidera permanen }\end{array}$ & 3 & 3 & 9 & Tinggi \\
\hline & & $\begin{array}{l}\text { Penumpukan berkas terlalu tinggi, } \\
\text { potensi tertimpa tumpukan berkas }\end{array}$ & Cidera anggota tubuh & 3 & 2 & 6 & Sedang \\
\hline & & $\begin{array}{l}\text { Terbatasnya udara (kadar oksigen) } \\
\text { di area gudang. }\end{array}$ & Cepat lelah & 4 & 3 & $\begin{array}{l}1 \\
2\end{array}$ & Tinggi \\
\hline \multirow[t]{6}{*}{ Engineering } & $\begin{array}{l}\text { Pemeliharaan } \\
\text { Air Conditioner }\end{array}$ & $\begin{array}{l}\text { Tersengat aliran listrik saat } \\
\text { pengecekan }\end{array}$ & $\begin{array}{l}\text { Tubuh akan mengalami } \\
\text { kesemutan atau kejutan }\end{array}$ & 3 & 2 & 6 & Sedang \\
\hline & & $\begin{array}{l}\text { Freon tidak sesuai kapasitas yang } \\
\text { berpotensi memicu ledakan }\end{array}$ & Kematian & 2 & 4 & 8 & Tinggi \\
\hline & $\begin{array}{l}\text { Penggunaan } \\
\text { Scaffolding }\end{array}$ & $\begin{array}{l}\text { Scaffolding berkarat dan rapuh, } \\
\text { Terjatuh dari scaffolding }\end{array}$ & Cidera anggota tubuh & 3 & 3 & 9 & Tinggi \\
\hline & & $\begin{array}{l}\text { Tidak ada identifikasi peringatan } \\
\text { penggunaan scaffolding, potensi } \\
\text { menabrak }\end{array}$ & Cidera anggota tubuh & 2 & 2 & 4 & Rendah \\
\hline & $\begin{array}{l}\text { Perawatan } \\
\text { Graoud tank } \\
\text { dan Rooftank }\end{array}$ & $\begin{array}{l}\text { Pompa booster rusak dan macet, } \\
\text { saluran air tidak mengalir } \\
\text { menyebabkan timbulnya kebauan }\end{array}$ & Gangguan pernapasan & 3 & 3 & 9 & Tinggi \\
\hline & & $\begin{array}{l}\text { Penggunaan kaporit yang } \\
\text { berlebihan }\end{array}$ & Iritasi pada kulit & 3 & 2 & 6 & Sedang \\
\hline
\end{tabular}


Tabel 4. Penilaian Risiko PT. Wika Realty Apartemen Tamansari Skylounge Tangerang (Lanjutan)

\begin{tabular}{|c|c|c|c|c|c|c|c|}
\hline Divisi & Aktivitas & Uraian Potensi Bahaya & Dampak Risiko & & & $\begin{array}{c}\text { nent } \\
\mathrm{S}\end{array}$ & $\begin{array}{l}\text { Risk } \\
\text { Level }\end{array}$ \\
\hline \multirow{2}{*}{ Engineering } & \multirow{2}{*}{$\begin{array}{l}\text { Perbaikan } \\
\text { aliran listrik } \\
\text { gedung }\end{array}$} & \multicolumn{2}{|c|}{$\begin{array}{l}\text { Tidak memperhatikan kondisi aliran Kematian } \\
\text { listrik yang dicek, potensi kesetrum }\end{array}$} & 1 & 5 & 5 & Tinggi \\
\hline & & $\begin{array}{l}\text { Penggunaan alat pelindung diri } \\
\text { yang tidak sesuai }\end{array}$ & $\begin{array}{l}\text { Cidera berat bahkan bisa } \\
\text { cidera permanen }\end{array}$ & 3 & 3 & 9 & Tinggi \\
\hline \multirow[t]{4}{*}{ Parking } & \multirow[t]{2}{*}{$\begin{array}{l}\text { Pengaturan } \\
\text { Area Parkir }\end{array}$} & $\begin{array}{l}\text { Tertabrak Kendaraan yang } \\
\text { keluar/masuk }\end{array}$ & Luka anggota tubuh & 2 & 3 & 6 & Sedang \\
\hline & & $\begin{array}{l}\text { Suara Mesin Kendaraan dan Asap } \\
\text { Knalpot }\end{array}$ & $\begin{array}{l}\text { Penurunan pendengaran dan } \\
\text { gangguan pernapasan }\end{array}$ & 3 & 2 & 6 & Sedang \\
\hline & \multirow[t]{2}{*}{$\begin{array}{l}\text { Pengaturan } \\
\text { Lalu Lintas }\end{array}$} & $\begin{array}{l}\text { Tertabrak Kendaraan yang } \\
\text { keluar/masuk }\end{array}$ & Luka anggota tubuh & 2 & 3 & 6 & Sedang \\
\hline & & $\begin{array}{l}\text { Suara Mesin Kendaraan dan Asap } \\
\text { Knalpot }\end{array}$ & $\begin{array}{l}\text { Penurunan pendengaran dan } \\
\text { gangguan pernapasan }\end{array}$ & 3 & 2 & 6 & Sedang \\
\hline \multirow[t]{11}{*}{$\begin{array}{l}\text { House- } \\
\text { keeping }\end{array}$} & \multirow{3}{*}{$\begin{array}{l}\text { Pembersihan } \\
\text { dalam } \\
\text { Gedung }\end{array}$} & $\begin{array}{l}\text { Tidak ada tanda bahwa lantai licin } \\
\text { atau baru di pel, potensi terjatuh }\end{array}$ & Cidera anggota tubuh & 3 & 2 & 6 & Sedang \\
\hline & & $\begin{array}{l}\text { Penggunaan cairan pel berlebihan } \\
\text { menyebabkan bau menyengat }\end{array}$ & Gangguan Pernapasan & 2 & 2 & 4 & Rendah \\
\hline & & Bagian alat kebersihan yang tajam & Cidera Anggota tubuh & 3 & 2 & 6 & Sedang \\
\hline & \multirow{2}{*}{$\begin{array}{l}\text { Pembuangan } \\
\text { Sampah }\end{array}$} & Tempat penyimpanan B3 bocor & Menghirup udara B3 & 3 & 3 & 9 & Tinggi \\
\hline & & $\begin{array}{l}\text { Pembuangan sampah B3 dan non } \\
\text { B3 di campur }\end{array}$ & Menghirup udara B3 & 3 & 3 & 9 & Tinggi \\
\hline & \multirow{4}{*}{$\begin{array}{l}\text { Pencucian } \\
\text { Alat } \\
\text { Makanan }\end{array}$} & $\begin{array}{l}\text { Jari tangan tergores alat } \\
\text { makan/dapur yang tajam }\end{array}$ & Luka Jari tangan & 2 & 2 & 4 & Rendah \\
\hline & & $\begin{array}{l}\text { Posisi tubuh pekerja pencuci piring } \\
\text { dengan membungkuk }\end{array}$ & Cidera punggung & 3 & 2 & 6 & Sedang \\
\hline & & $\begin{array}{l}\text { Penggunaan cairan pencuci alat } \\
\text { makan berlebihan }\end{array}$ & $\begin{array}{l}\text { Kulit permukaan telapak } \\
\text { tangan \& jari tangan } \\
\text { mengelupas }\end{array}$ & 2 & 2 & 4 & Rendah \\
\hline & & Alat pencuci berkarat & $\begin{array}{l}\text { Jari atau tangan tergores } \\
\text { karat }\end{array}$ & 3 & 2 & 6 & Sedang \\
\hline & \multirow{2}{*}{$\begin{array}{l}\text { Penggunaan } \\
\text { Chemical } \\
\text { Pembersih } \\
\text { Lantai }\end{array}$} & \multirow{2}{*}{$\begin{array}{l}\text { Pengeringan/Pemerasan alat pem- } \\
\text { bersihan lantai tanpa sarung tangan } \\
\text { Penggunaan chemical yang ber-- } \\
\text { lebihan menyebabkan bau } \\
\text { menyengat }\end{array}$} & Kulit tangan luka & 2 & 2 & 4 & Rendah \\
\hline & & & Gangguan pernapasan & 2 & 3 & 6 & Sedang \\
\hline Security & $\begin{array}{l}\text { Keamanan } \\
\text { Gedung }\end{array}$ & Bahaya pencurian & $\begin{array}{l}\text { Terluka bahkan sampai } \\
\text { meninggal dunia }\end{array}$ & 1 & 5 & 5 & Tinggi \\
\hline \multirow{7}{*}{$\begin{array}{l}\text { Vendor/ } \\
\text { Subcon }\end{array}$} & \multirow{3}{*}{$\begin{array}{l}\text { Perawatan } \\
\text { Genset }\end{array}$} & \multirow{3}{*}{$\begin{array}{l}\text { Tersetrum aliran listrik } \\
\text { Area Kebisingan tinggi karena } \\
\text { suara dari genset diatas } 90 \mathrm{Dba} \\
\text { Tangan tergencet mesin atau tools } \\
\text { saat melakukan perawatan }\end{array}$} & Cidera berat & 2 & 4 & 8 & Tinggi \\
\hline & & & Penurunan pendengaran & 5 & 2 & 10 & Tinggi \\
\hline & & & Luka tangan & 3 & 2 & 6 & Sedang \\
\hline & \multirow[t]{2}{*}{$\begin{array}{l}\text { Pembuangan } \\
\text { Sampah }\end{array}$} & \multirow{2}{*}{$\begin{array}{l}\text { Bahan Kimia tidak dilengkapi MSDS } \\
\text { Salah penggunaan bahan kimia } \\
\text { Alat spray tidak aman }\end{array}$} & Terpapar bahan kimia & 3 & 3 & 9 & Tinggi \\
\hline & & & Terpapar bahan kimia & 2 & 3 & 6 & Sedang \\
\hline & \multirow{2}{*}{$\begin{array}{l}\text { Pembuangan } \\
\text { Limbah Se- } \\
\text { wage Treat- } \\
\text { ment Plant }\end{array}$} & \multirow{2}{*}{$\begin{array}{l}\text { Bahan Kimia tidak dilengkapi MSDS } \\
\text { salah penggunaan bahan kimia } \\
\text { Motor blower terbakar, } \\
\text { menyebabkan bau tidak sedap }\end{array}$} & Terpapar bahan kimia & 3 & 3 & 9 & Tinggi \\
\hline & & & Gangguan pernapasan & 2 & 3 & 6 & Sedang \\
\hline
\end{tabular}

Aktivitas kegiatan pada PT. Wika Realty apartemen Tamansari Skylounge mempunyai 45 aktivitas yang mempunyai potensi dan risiko bahaya dengan 15 berada dalam kategori tinggi, 23 dalam kategori sedang dan 7 dalam kategori rendah. Persentase perbandingan dari 6 divisi dengan jumlah potensi bahayanya, divisi Staff management building 31\%, Divisi Engineering 18\%, Divisi Parking 9\%, Divisi Housekeeping $24 \%$, Security $2 \%$, Vendor/Subcon $16 \%$. Divisi yang mempunyai jumlah potensi bahaya terbanyak yaitu divisi Staff management building $31 \%$. Sedangkan yang mempunyai jumlah potensi bahaya paling sedikit yaitu Security 2\% (Gambar 3).

Persentase perbandingan antara tingkat risiko dengan jumlah semua bahaya diperoleh tingkat risiko tinggi 33\%, tingkat risiko Sedang $51 \%$, tingkat risiko rendah $16 \%$. Potensi bahaya dinyatakan bernilai rendah karena hanya menimbulkan cidera ringan atau tidak menimbulkan kerugian bagi perusahaan. Potensi bahaya 
dinyatakan bernilai sedang jika menimbulkan cidera berat tetapi tidak sampai cacat tetap atau bagi perusahaan mengalami kerugian financial sedang. Potensi bahaya dinyatakan bernilai tinggi karena memicu cidera parah dan cacat tetap atau memicu dampak serius bagi kelangsungan bisnis perusahaan. Persentase tertinggi untuk tingkat risiko yaitu Tingkat risiko sedang 51\% (Gambar 4).

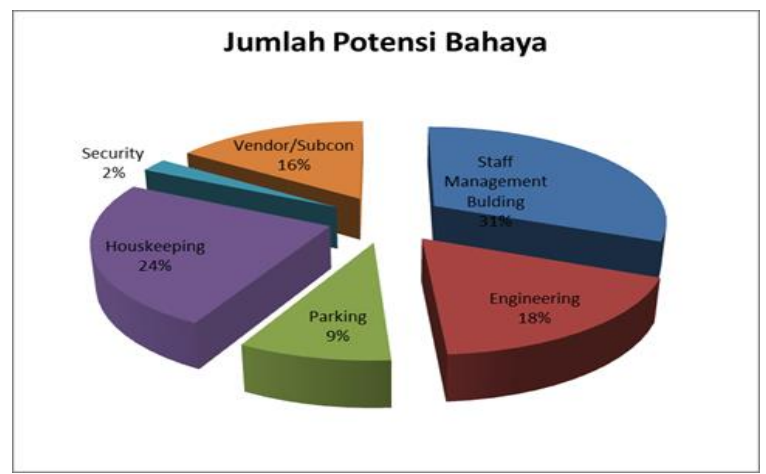

Gambar 3. Jumlah Potensi Bahaya

Usulan perbaikan untuk mengurangi risiko bahaya ke 6 divisi PT. Wika Realty apartemen
Tamansari Skylounge Tangerang dengan perbaikan untuk tingkat risiko tinggi (Tabel 5). Pengendalian potensi yang paling efektif adalah dengan mengeliminasi jenis pekerjaan yang mempunyai risiko tinggi (Supriyadi \& Ramdan, 2017). Hasil penelitian menunjukkan pengendalian bahaya masih dalam tahap rekayasa engineering, pengendalian administratif dan alat pelindung diri (APD) sesuai dengan potensi risiko yang terjadi.

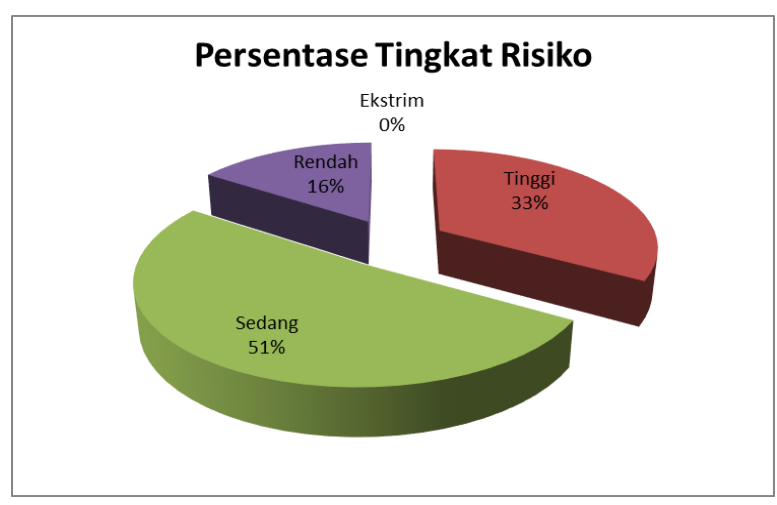

Gambar 4. Persentase Tingkat Risiko

Tabel 5. Usulan Perbaikan

\begin{tabular}{|c|c|c|c|}
\hline Divisi & Potensi Bahaya & Penyebab Bahaya & Usulan Perbaikan \\
\hline \multirow[t]{2}{*}{$\begin{array}{l}\text { Staff } \\
\text { Management } \\
\text { Building }\end{array}$} & $\begin{array}{l}\text { Konsleting pada Alat } \\
\text { elektronik yang berpotensi } \\
\text { kebakaran }\end{array}$ & $\begin{array}{l}\text { Instalasi kabel tidak } \\
\text { beraturan }\end{array}$ & $\begin{array}{l}\text { Membuat safety cover untuk } \\
\text { instalasi kabel agar tidak kesetrum } \\
\text { dan mencegah konsleting listrik }\end{array}$ \\
\hline & $\begin{array}{l}\text { Terbatasnya udara (kadar } \\
\text { oksigen) di area gudang. }\end{array}$ & $\begin{array}{l}\text { Kurangnya sirkulasi } \\
\text { udara }\end{array}$ & Menambah Blower di area gudang \\
\hline \multirow[t]{4}{*}{ Engineering } & $\begin{array}{l}\text { Freon tidak sesuai kapasitas } \\
\text { sehingga } \quad \text { berpotensi } \\
\text { memicu ledakan }\end{array}$ & $\begin{array}{l}\text { Tidak ada indikator } \\
\text { level pada pressure } \\
\text { gauge freon }\end{array}$ & $\begin{array}{l}\text { Membuat indikator level pada } \\
\text { pressure gauge Freon agar } \\
\text { kapasitas pengisiannya terkontrol }\end{array}$ \\
\hline & Terjatuh dari scaffolding & $\begin{array}{l}\text { Scaffolding berkarat } \\
\text { dan rapuh }\end{array}$ & $\begin{array}{l}\text { Membuat cek list pemeriksaan } \\
\text { scaffolding agar scaffolding tetap } \\
\text { layak digunakan }\end{array}$ \\
\hline & $\begin{array}{l}\text { saluran air tidak mengalir } \\
\text { menyebabkan timbulnya } \\
\text { kebauan }\end{array}$ & $\begin{array}{l}\text { Pompa booster } \\
\text { rusak dan macet }\end{array}$ & $\begin{array}{l}\text { Membuat cek list pemeriksaan } \\
\text { pompa booster untuk mencegah } \\
\text { kerusakan mendadak }\end{array}$ \\
\hline & $\begin{array}{l}\text { Penggunaan alat pelindung } \\
\text { diri yang tidak sesuai }\end{array}$ & Sikap pekerja & $\begin{array}{l}\text { Membuat standar penggunaan APD } \\
\text { sesuai dengan pekerjaannya dan } \\
\text { dipasang pada setiap pekerjaan } \\
\text { tersebut }\end{array}$ \\
\hline \multirow[t]{2}{*}{ House Keeping } & $\begin{array}{l}\text { Tempat penyimpanan B3 } \\
\text { bocor }\end{array}$ & $\begin{array}{l}\text { Belum ada inspeksi } \\
\text { Rutin }\end{array}$ & $\begin{array}{l}\text { Melakukan inspeksi rutin tempat } \\
\text { penyimpanan B3 }\end{array}$ \\
\hline & $\begin{array}{l}\text { Pembuangan sampah B3 } \\
\text { dan non B3 dicampur. }\end{array}$ & $\begin{array}{l}\text { Hanya ada satu } \\
\text { tempat sampah }\end{array}$ & $\begin{array}{l}\text { Membuat tempat sampah B3 dan } \\
\text { Non B3 secara terpisah }\end{array}$ \\
\hline Security & Bahaya pencurian & Pencuri & $\begin{array}{l}\text { Mengadakan pelatihan beladiri } \\
\text { secara rutin untuk security }\end{array}$ \\
\hline \multirow[t]{2}{*}{ Vendor/Subcon } & $\begin{array}{l}\text { Area Kebisingan tinggi } \\
\text { karena suara yang di keluar } \\
\text { oleh genset diatas } 90 \text { Dba }\end{array}$ & Suara kebisingan & $\begin{array}{l}\text { Di area Genset disediakan double } \\
\text { protector untuk APD }\end{array}$ \\
\hline & $\begin{array}{llr}\text { Bahan } & \text { Kimia } & \text { tidak } \\
\text { dilengkapi } & \text { MSDS, Salah } \\
\text { penggunaan bahan kimia }\end{array}$ & Tidak ada MSDS & $\begin{array}{l}\text { Bahan berbahaya dan beracun (B3) } \\
\text { dilengkapi material safety data } \\
\text { sheet (MSDS) }\end{array}$ \\
\hline
\end{tabular}




\section{KESIMPULAN}

Hasil pengukuran metode HAZOPS dari 6 divisi apartemen Tamansari Skylounge Tangerang diperoleh potensi bahaya divisi Staff management building 31\%, Divisi Engineering 18\%, Divisi Parking 9\%, Divisi Housekeeping $24 \%$, Security $2 \%$, dan Vendor/Subcon $16 \%$. Divisi yang mempunyai jumlah potensi bahaya terbanyak yaitu divisi Staff management building $31 \%$. Sedangkan yang mempunyai jumlah potensi bahaya paling sedikit yaitu Security $2 \%$. Hasil analisis tingkat risiko yaitu tingkat risiko Tinggi $33 \%$, tingkat risiko Sedang $51 \%$, tingkat risiko rendah $16 \%$. Jadi potensi bahaya yang tingkat risiko ekstrim tidak ada pada pengelolaan gedung apartemen Tamansari Skylounge Tangerang. Persentase tertinggi untuk tingkat risiko yaitu tingkat risiko sedang 51\%. Perbaikan dilakukan dengan mengacu ke hirarki pengendalian potensi bahaya: eliminasi, substitusi, rekayasa engineering, pengendalian administratif dan alat pelindung diri (APD). Untuk penelitian selanjutnya bisa ditambahkan analisa mengenai biaya kecelakaan agar terlihat kerugian bagi perusahaan

\section{DAFTAR PUSTAKA}

Achada P.N., \& Anis, M. (2016). Manajemen Resiko Kesehatan Dan Keselamatan Kerja Supermarket Dengan Metode Hazard And Operability Study (Hazop) Melalui Perangkingan Standar As/Nzs Dan Root Causes Analysis (Studi Kasus: Assalaam Hypermarket, Pabelan, Kartosura) Skripsi. Solo: Universitas Muhammadiyah Surakarta. http://eprints.ums.ac.id/46101/

Ahmad, A. C., Mohd Zin, I. N., Othman, M. K., \& Muhamad, N. H. (2016). Hazard Identification, Risk Assessment and Risk Control (HIRARC) Accidents at Power Plant. MATEC Web of Conferences, 66, 1-6. https://doi.org/10.1051/matecconf/20166600 105

Alfatiyah, R., Bastuti, S., \& Prasetiyo, T. T. (2017). Analisis Pengaruh Lingkungan Kerja Serta Jaminan Sosial Terhadap Keselamatan Dan Kesehatan Kerja (K3) Dengan Metode Regresi Linear Berganda Pada Pt. Delta Citra Mandiri. Prosiding Seminar IImiah Nasional: "Membangun Paradigma Kehidupan Melalui Multidisiplin IImu, 1-3. http://openjournal.unpam.ac.id/index.php/Pr oceedings/article/view/764

Arif, M., \& Syahri, M.I. (2014). Analisa Potensi Bahaya Dengan Menggunakan Metode Job Safety Analysis (JSA) Pada Proses Coal Chain Di Pertambangan Batubara $x$ Tahun 2014. Lingkungan Dan Keselamatan Kerja, 3(3), https://jurnal.usu.ac.id/index.php/lkk/article/v iew/7617

Bastuti, S. (2020). Analisis Risiko Kecelakaan Kerja Dengan Metode Failure Mode And Effect Analysis ( FMEA) dan Fault Tree Analysis ( FTA ) untuk Menurunkan Tingkat Risiko Kecelakaan Kerja (PT. Berkah Mirza Insani). TEKNOLOGI: Jurnal IImiah Dan Teknologi, 2(1), 48-52. http://www.openjournal.unpam.ac.id/index.p hp/TKG/article/view/3909

Cameron, I., Mannan, S., Németh, E., Park, S., Pasman, H., Rogers, W., \& Seligmann, B. (2017). Process hazard analysis, hazard identification and scenario definition: Are the conventional tools sufficient, or should and can we do much better? Process Safety and Environmental Protection, 110, 53-70. https://doi.org/https://doi.org/10.1016/j.psep. 2017.01.025

Carrascosa, C., Millán, R., Saavedra, P., Jaber, J. R., Raposo, A., \& Sanjuán, E. (2016). Identification of the risk factors associated with cheese production to implement the hazard analysis and critical control points (HACCP) system on cheese farms. Journal of Dairy Science, 99(4), 2606-2616. https://doi.org/https://doi.org/10.3168/jds.20 15-10301

Kim, K., Kang, H., \& Kim, Y. (2015). Risk Assessment for Natural Gas Hydrate Carriers: A Hazard Identification (HAZID) Study. Energies, 8(4), 3142-3164. https://doi.org/10.3390/en8043142

Mansur, A., \& Nasution, M. I. (2016). Identification of Behavior Based Safety by Using Traffic Light Analysis to Reduce Accidents. IOP Conference Series: Materials Science and Engineering, 105(1), 1-9. https://doi.org/10.1088/1757899X/105/1/012033

Restuputri, D. P., \& Sari, R. P. D. (2015). Analisis kecelakaan kerja dengan menggunakan metode Hazard and Operability Study (HAZOP). Jurnal Ilmiah Teknik Industri, 14(1), 24-35. http://journals.ums.ac.id/index.php/jiti/article /view/621

Siddiqui, N. A., Nandana, A., Sharmaa, M., \& Srivastavaa, A. (2014). Risk Management Techniques HAZOP \& HAZID Study. International Journal on Occupational Health \& Safety, Fire \& Environment - Allied Sciences, 1(1), 5-8. https://ohsfejournal.com/?p=116

Sugarindra, M., Suryoputro, M. R., \& Novitasari, A. T. (2017). Hazard Identification and Risk Assessment of Health and Safety Approach 
JSA (Job Safety Analysis) in Plantation Company. IOP Conference Series: Materials Science and Engineering, 215, 1-10. https://doi.org/10.1088/1757899X/215/1/012029

Suhardi, B., Widyo Laksono, P., Ayu V.E, A., Mohd.Rohani, J., \& Shy Ching, T. (2018). Analysis of the Potential Hazard Identification and Risk Assessment (HIRA) and Hazard Operability Study (HAZOP): Case Study. International Journal of Engineering \& Technology, 7(3.24), 1-7. https://doi.org/10.14419/ijet.v7i3.24.17290

Supriyadi, Nalhadi, A., \& Rizaal, A. (2015). Identifikasi Bahaya dan Penilaian Risiko K3 Pada Tindakan Perawatan dan Perbaikan Menggunakan Metode HIRARC pada PT. X. Seminar Nasional Riset Terapan, 05, 281286.

https://ejurnal.Ippmunsera.org/index.php/senasset/a rticle/view/474
Supriyadi, S., \& Ramdan, F. (2017). Identifikasi Bahaya Dan Penilaian Risiko Pada Divisi Boiler Menggunakan Metode Hazard Identification Risk Assessment and Risk Control (HIRARC). Journal of Industrial Hygiene and Occupational Health, 1(2), 161-177.

https://doi.org/10.21111/jihoh.v1i2.892

Ulva, F. (2019). Hubungan Tindakan Kerja Dan Kondisi Kerja Dengan Kecelakaan Kerja Pada Pekerja Bagian Tiang Besi Di Pt. X Kota Padang Tahun 2017. Jurnal Keperawatan Abdurrab, 3(1), 44-50. https://doi.org/10.36341/jka.v3i1.716

Zhang, S., Sulankivi, K., Kiviniemi, M., Romo, I., Eastman, C. M., \& Teizer, J. (2015). BIMbased fall hazard identification and prevention in construction safety planning. Safety Science, 72, 31-45. https://doi.org/https://doi.org/10.1016/j.ssci. 2014.08.001 